\title{
Knowledge-sharing Dilemmas*
}

\author{
Ángel Cabrera, Elizabeth F. Cabrera
}

Ángel Cabrera Instituto de Empresa, Madrid, Spain

Elizabeth $F$. Cabrera

Department of Business

Administration, Universidad Carlos III, Madrid, Spain

\section{Abstract}

The exchange of information among organizational employees is a vital component of the knowledge-management process. Modern information and telecommunication technology is available to support such exchanges across time and distance barriers. However, organizations investing in this type of technology often face difficulties in encouraging their employees to use the system to share their ideas. This paper elaborates on previous research, suggesting that sharing personal insights with one's co-workers may carry a cost for some individuals which may yield, at the aggregate level, a co-operation dilemma, similar to a public-good dilemma. A review of the research on different types of public-good dilemmas provides some indications of the specific interventions that may help organizations encourage the kind of social dynamics that will increase overall knowledge sharing. These interventions can be classified into three categories: interventions aimed at restructuring the pay-offs for contributing, those that try to increase efficacy perceptions, and those that make employees' sense of group identity and personal responsibility more salient.

Descriptors: organizational knowledge, knowledge management, co-operation, social dilemmas

\section{Introduction}

According to a recent industry survey (KPMG 2000), 81 percent of the leading organizations in Europe and the United States say they have, or are at least considering adopting, some kind of knowledge-management system. The majority of these firms become involved in knowledge-management initiatives with the goal of gaining competitive advantage ( 79 percent), increasing marketing effectiveness (75 percent), developing a customer focus (72 percent), or improving product innovation (64 percent). Knowledge management is normally used to refer to those managerial practices that are implemented with the main (or sole) objective of creating, storing, disseminating and exploiting organizational knowledge (Davenport et al. 1998). Knowledge-management practices can be of a very diverse nature: they may include information technology (e.g. Anand et al. 1998), organizational structure (Wenger and Snyder 1999; Moore and Birkinshaw 1998), and new human-resource policies (Ulrich 1998). In general, tech- 
nological solutions tend to prevail. Knowledge-management projects are more likely to be led by the IT department ( 22 percent) than by human resources (5 percent), marketing (16 percent) or operations ( 4 percent), and are often built around some kind of intranet, shared database, or groupware software that allows people to communicate with one another, share ideas, and engage in discussions (KPMG 2000).

Two factors have most likely contributed to this extraordinary interest in knowledge management. First, there is a growing conviction among company managers, consultants, and scholars that organizational knowledge may constitute a key strategic resource (see Boisot 1998; Spender 1996; or Nanda 1996). Knowledge can be seen as an intangible asset which is unique, path dependent, causally ambiguous, and hard to imitate or substitute. These characteristics make knowledge a potential source of competitive advantage, and, consequently, the logical target of managerial attention. The second factor contributing to the adoption of knowledge-management solutions has to do with the recent developments in information and communication technologies (Boland et al. 1994; Olson et al. 1993; Fowler 2000; Davenport and Prusak 1998). The development and widespread adoption of global networks and communication protocols have not only made it possible, but also economically feasible, to interconnect employees in large and geographically distributed companies, allowing them to exchange documents and virtually any type of multimedia content (Anand et al. 1998). As we will see, the exchange of information among employees constitutes a key component in the creation and management of collective wisdom, and, consequently, the availability of tools that support such exchanges facilitates tremendously the implementation of knowledge-management systems.

Having been a major driving force in the diffusion of knowledge-management ideas, it is fair to say that information technology is pretty much ahead of the game. Only 7 percent of the companies surveyed by KPMG (2000) mentioned technology as a barrier for the successful implementation of knowledge management - a good indication that technology is doing its job. On the contrary, companies often face a number of non-technological problems that jeopardize the potential benefits of investments in knowledge-management systems. For example, employees may not share what they know with other co-workers due to insufficient understanding of the benefits of doing so, or because they somehow cannot manage to integrate such tasks into their everyday duties. Some employees may not have enough time to share their experiences, or to learn how to use the available information systems. Also, some employees may fail to see a personal benefit from sharing knowledge, or they may perceive insufficient support from the company's top management to apply new ideas to their work (KPMG 2000).

Several scholars and consultants (e.g. Davenport et al. 1998; Davenport and Prusak 1998; Nevis et al. 1995; DeLong and Fahey 2000; Gupta and Govindarajan 2000) have argued that creating a culture that values creativity, continuous improvement and the sharing of ideas is necessary for 
knowledge-management initiatives to succeed. For an organization to manage its knowledge assets effectively, it needs to have employees who are motivated to explore new market opportunities, new work procedures or new products, and who are willing to apply new ideas to their own work; it needs structures and work systems that are flexible enough to admit innovative changes, and job definitions that grant employees a fair level of autonomy; and, very importantly, it needs to set up mechanisms by which new ideas are shared (Gupta and Govindarajan 2000). The sharing of ideas among employees is only one of several processes underlying collective knowledge within an organization, but it is a key process, without which, a company may not be able to leverage its most valuable asset (Wasko and Faraj 2000; Jarvenpaa and Staples 2000; Nahapiet and Ghoshal 1998).

This paper focuses on the process of sharing valuable information and ideas among individuals in an organization. In particular, it presents a framework that helps in understanding the socio-psychological processes governing exchanges among employees, and one that may guide the design of interventions to successfully manage organizational knowledge. The framework borrows from sociological research on cooperation and thus enjoys a reasonable degree of supporting evidence from other disciplines that study human social behaviour. As we will explain, there is empirical evidence showing a parallel between knowledge-sharing behaviour and other social cooperation situations. Based on this connection, proposed and defended by other authors, we take a step forward to identify concrete interventions that can help resolve the cooperation dilemmas with regard to knowledge sharing within organizations. These interventions are cross-functional in nature: some of them relate to the design of information systems, others, to work structures, and yet others, to human-resource policies.

The rest of the paper is structured as follows: first, the notion of organizational knowledge, its strategic value for the firm, and the main processes by which it is created, stored and used are outlined. The concept of 'social dilemmas' is then introduced, and the framework that links the language of social dilemmas to knowledge management is described. Finally, drawing from the sociological research on social dilemmas, a series of potential interventions for managing organizational knowledge are presented and discussed.

\section{Organizational Knowledge and Knowledge Management}

According to the resource-based view of the firm, the key to a company's competitive advantage lies in its unique combination of physical, organizational and human assets (Wernerfelt 1984; Barney 1991). Specifically, to be a source of sustained competitive advantage, an asset must be valuable, rare and difficult to imitate or substitute. Several researchers have argued that organizational knowledge or capabilities meet these requirements and should, therefore, be considered a strategic asset (Lado and Wilson 1994; Spender 1996; Nanda 1996). Organizational knowledge results from the 
particular history of internal and external interactions and adaptation undergone by the organization. It represents the point that has been reached by the organization's learning processes at any given time and is thus intrinsically valuable for its activity (Levitt and March 1988; Nelson and Winter 1982; Winter 1996). Organizational knowledge is rare - and unique because it is path dependent, i.e. there are no two organizations that have undergone exactly the same history of learning experiences. Collective knowledge is hard to appropriate by third parties because of its supra-individual character and because it is made up of co-specialized capabilities (Nanda 1996), and it is difficult to imitate because it is causally ambiguous, i.e. it is embedded in a complex network of formal and informal interpersonal relationships and in a shared and often unspoken system of norms and beliefs (Sanchez and Heene 1997).

The most extended, yet debated, organizational theory of knowledge establishes a taxonomic distinction of organizational knowledge along two dimensions: degree of articulation and degree of aggregation (see Spender 1996; Nonaka and Takeuchi 1995; Blackler 1995; Lam 2000). According to how well it can be articulated, knowledge can be classified as tacit or explicit. Tacit knowledge includes hard-to-communicate skills, know-how or practical knowledge (e.g. being able to ride a bicycle, sell a financial product or build excellent automobiles). Explicit knowledge, on the contrary, refers to forms of knowledge that can easily be communicated to others (e.g. facts, concepts, frameworks). From the point of view of aggregation, we can distinguish between individual and collective forms of knowledge, that is, pieces of knowledge that are held by one person vs. knowledge that is embedded in the interactions among a group of people. The combination of the two dimensions creates four classes of knowledge: individual-tacit (or embodied knowledge, according to Blackler 1995), individual-explicit (embrained knowledge), collective-explicit (encoded knowledge) or collective-tacit (encultured and embedded knowledge). According to Nonaka (1994), organizational knowledge emerges from a series of ongoing transformations among these different types of knowledge which require that the ideas and skills of different individuals be divulged and combined into collective routines and shared knowledge bases, that encoded knowledge be internalized by individuals, and that individuals share their skills with one another.

Other authors (see Cook and Brown 1999; Tsoukas 1996; Blackler 1995) have defended alternative views of organizational knowledge that emphasize its situated, socially constructed, contextualized and dynamic character. These views depart from the somewhat disembodied, timeless, view predominant in resource-based views of knowledge (such as Nonaka's 1994; see also Cabrera and Allen 1999). While the debate remains as to how compatible these views may be (Merali 2000), there appears to be a general consensus around the idea that collective knowledge emerges from interaction and dialogue among the members of a community or an organization (Wenger and Snyder 1999). It is precisely on these interactions that most knowledge-management initiatives focus. 
Companies can pursue different knowledge-management strategies depending on what type of knowledge they consider most valuable. Hansen et al. (1999) analyzed the practices of different consulting firms and found that the knowledge-management approach that was adopted matched the business model of each firm (see also Moore and Birkinshaw 1998 for a discussion of knowledge management in global service firms). Large consulting firms such as Accenture or Ernst and Young, with a strong focus on information-system implementation, try to generate large revenues by developing solutions and methods that can be re-used many times with many clients. Strategy consultants such as McKinsey or Bain, on the other hand, generate high profit margins by providing highly customized solutions to unique client issues and charging high fees for their services. Accenture's knowledge-management approach consists of developing large electronic document and groupware systems that facilitate the codification, storage and diffusion of work methods. McKinsey, on the contrary, tries to develop professional networks that allow the sharing and dissemination of tacit knowledge.

These approaches illustrate how, in different ways, knowledge-management initiatives try to foster the sharing of knowledge, ideas and experiences, in whatever form, among individuals or groups. An interesting characteristic of knowledge is the fact that its value grows when it is shared: 'As one shares knowledge with other units, not only do those units gain information (linear growth); they share it with others and feed back questions, amplifications, and modifications that add further value for the original sender, creating exponential total growth' (Quinn et al. 1996: 8). Unlike standard economic transactions, information can be transacted over and over again without the transacting party ever giving up the value of the item being transacted, thus creating the possibility of endless returns. Nahapiet and Ghoshal (1998) argue that knowledge creation is the result of a double process of combination and exchange. Gradual knowledge creation requires the combination of previously unconnected pieces of knowledge, whereas radical innovations are based on novel conceptual distinctions, or novel ways of combining elements that might already have been associated. Either way, since the pieces of knowledge to be combined may reside in different parties, the exchange of information becomes a requisite for combination, and thus, for collective knowledge creation.

Given the importance of exchanging information, managers who are considering investing in knowledge-management systems may ask themselves some of the following questions: Why do people share, or not share information with co-workers? What motivates a person to give up personal knowledge to a third party? What are the main barriers that an organization may face when trying to foster knowledge sharing among its employees? And finally, what can an organization do to overcome those barriers?

A recent exploratory study by Jarvenpaa and Staples (2000) found that significant predictors of participation in computer-mediated information exchange were: personal propensity to share information, experienced com- 
fort with the use of computer technology, perceptions about the quality of content found in information systems, and the degree of task interdependence experienced by each employee. Using open-ended questions, Wasko and Faraj (2000) surveyed users of three computer-related Usenet newsgroups that served as cross-organizational communities of practice. Their analysis of the responses gathered showed that people participated because they wanted to feel part of, and promote, a professional community that they valued, and because, by doing so, this helped them to stay up-to-date with current ideas and innovations. They also reported that they had volunteered advice to others in the community, because they found it both enjoyable and satisfying to help others, and because they considered it due reciprocity for the help they themselves had obtained from that community.

As more empirical data is obtained to help us respond to the questions raised by the implementors of knowledge-management systems, we feel it is important to understand the interrelations between the different variables at play and to explore whether prior research in other areas of human behaviour may provide adequate preliminary pointers. The goal of this paper is to take a step in that direction, by analyzing the social dynamics underlying knowledge sharing, and by linking current managerial problems to a rich research tradition in social cooperation, thereby making it easier to identify potential organizational solutions. We are not the first ones to connect those two important research areas. Our contribution lies in the clarification of the interconnections and the exploration of the organizational implications of treating knowledge-sharing as a problem of social cooperation.

\section{Knowledge Sharing and Social Dilemmas}

According to some empirical work by Connolly and Thorn (1990), knowledge sharing can be conceptualized as a particular case of a paradigmatic social situation known as a social dilemma. Social dilemmas describe paradoxical situations in which individual rationality - simply trying to maximize individual pay-off - leads to collective irrationality (Kollock 1998). A popular example of a social dilemma is the tragedy of the commons (Hardin 1968), a situation in which a group of herders has open access to a shared property where they can let their cows graze. From the point of view of each individual herder, there is a clear benefit in letting as many cows as possible onto the common, but if everyone did that, the common would be damaged to the point at which no one would be able to benefit from it. This situation constitutes a dilemma because individual attempts to maximize pay-off can result in collective damage.

Social dilemmas have attracted the curiosity of social scientists for over 50 years, because (a) they appear to be canonic representations of many reallife situations, and (b) they are schematic enough to allow the application of a variety of powerful research methods, including mathematical model- 
ling, psychological experimentation, sociological and historical analysis. As a consequence of such research efforts, we now understand the factors reasonably well that so often prevent cooperation, and we have clues as to what kinds of interventions may increase the chances of cooperation (Kollock 1998). The 'tragedy of the commons' is usually referred to as a resource dilemma given that 'collective cooperation leads to a serious threat of the depletion of future resources' (Van Lange et al. 1992: 11).

Another type of social dilemma is the public-good dilemma. A public good constitutes a shared resource from which every member of a group may benefit, regardless of whether or not they personally contribute to its provision, and whose availability does not diminish with use (Olson 1965). Public television and public parks are examples of public goods. We can enjoy public television whether or not we pay taxes, and our enjoyment of it does not diminish its availability to others. According to several researchers of knowledge management (Wasko and Faraj 2000; Connolly and Thorn 1990; Connolly et al. 1992; Kalman 1999; Monge et al. 1998), organizational knowledge can also be considered a public good. We can improve our work performance by employing methods and ideas available from co-workers, and our use of these ideas does not diminish their potential value to others.

Since access to a public good is not restricted to contributors only, there is a temptation for individuals to free-ride, i.e. to enjoy the resource without contributing to its provision (Sweeney 1973). After all, withholding from cooperating yields the best individual utility, regardless of what everyone else in the group does. If everyone else cooperates and I do not, I enjoy the good for free. If no one else or very few others cooperate, I will be saving a wasted contribution. For this reason, defecting, or not contributing, in a public-good dilemma is technically considered to be a dominant strategy, i.e. a strategy that yields immediate positive returns to any participant, at any time during the interaction, regardless of the actions of other participants (Dawes 1980).

The problem is that most people in a public-good situation would be happier enjoying the good at the cost of their individual contribution than not enjoying the good and saving that cost. If there were an assurance that everybody else was going to pay his or her share, most people would very gladly contribute as well. This is where the dilemma resides: if everyone acted 'rationally', according to the dominant strategy, no one would cooperate, and everyone would end up suffering the consequences. This situation is usually referred to as a deficient equilibrium. It is an equilibrium situation because, once it is reached, there is no individual incentive to break it. It is deficient because the entire group suffers a non-optimal outcome. In a sense, once the deficient equilibrium is reached, there appears to be a social fence that keeps the group from reaching the benefits of cooperation (Messick and Brewer 1983).

Now consider the choice faced by an employee who has had the opportunity to develop some new skills or methods that, she believes, could be of great value to some of her co-workers. With relatively little effort, this per- 
son could reflect on the nature of the new methods, put together a brief document describing their rationale and potential benefits, and distribute the document to her co-workers. The document could help other people save time, improve results or come up with yet more ideas that could add significant value to the company as a whole. But why should she? From an individual standpoint there are some benefits, but there may also be significant costs. On the positive side, she may gain expert status within the organization, may receive public praise from the top management or may simply feel personally fulfilled by having contributed to other people's professional development. Yet, as modest as it may be, there is a real cost in sharing the idea. Putting the documents together and making the contribution consumes valuable time that might otherwise be invested in tasks with clearer returns (sales commissions, measurable performance). Also, in organizations with a competitive internal work environment, the contributor of an idea may be assuming a great deal of personal vulnerability by revealing the secrets of his or her own competitive edge. Depending on the relative weight of these costs and benefits, some individuals may feel that they are better off hoarding, rather than sharing, what they know.

When managers were asked by the KPMG study (2000) what problems were hindering participation rates in knowledge-exchange systems in their companies, many of them confirmed that people did not seem to have enough time to participate, that they saw little reward for sharing their knowledge, or that they simply thought their efforts were wasteful re-inventions of the wheel. As happens in many other public-good situations, it only takes but a few group members to feel this way, for the group to get trapped in a non-cooperating deficient equilibrium.

Contributing with ideas and information to one's organization is quite different from contributing with money to, say, build a public park or a road. In the latter case, the cost of the contribution amounts to the value of the contribution itself - if I chip in 20 , I experience a cost of exactly that much. When sharing a piece of information, the cost of the contribution does not lie in the contribution itself, among other reasons because one does not lose an idea as a result of the transaction (knowledge is not a 'commodity'). The cost, as explained above, has to do with the process of making that idea available, as well as with the social dynamics associated with it. Despite this clear difference with respect to classic public goods, Connolly and Thorn (1990) found evidence supporting the idea that the public-good scheme is a fair representation of knowledge-sharing situations. An individual is assuming a greater or lesser (perhaps even negative) cost when making an idea available to a community, and the community enjoys the benefits of such a contribution independently of which members have contributed. 


\section{How Can the Social Fence Be Scaled?}

Why do some people choose to cooperate in public-good situations? As mentioned earlier, there are perceived benefits of contributing, as well as costs. Some people may expect that their contributions will earn them a good reputation and improve their status within their social group. Others may choose to participate because it gives them positive feelings of sociability or of 'doing the right thing' (Wasko and Faraj 2000; Kalman 1999). Perhaps others do so in hopes of reciprocity, that is they trust that their participation will encourage others to follow (Wasko and Faraj 2000; Axelrod 1984). Despite these potential incentives, research has shown that there tends to be an under-supply of contributions in social-dilemma situations. For example, in Connolly et al.'s (1992) study, one third of the participants refused to contribute to a discretionary database, even when the cost was minimal.

From a management standpoint, we would like to know what possible interventions could help an organization scale the social fence and move towards a scenario where everyone cooperates. Research on social cooperation (see reviews by Kollock 1998, or Messick and Brewer 1983) has discovered many factors that influence levels of participation or contribution to a public good. We have organized a number of these factors into three main areas. After reviewing the literature regarding the influence of each of the factors on cooperation, we suggest organizational interventions that may increase levels of employee participation in knowledge-sharing programmes.

The first potential solution to knowledge-sharing dilemmas consists of restructuring the pay-off function. This can be accomplished by either reducing the perceived costs or increasing the perceived benefits of contributing. The second type of solution focuses on increasing perceived efficacy of individual contributions. Individuals are more willing to participate if they believe their contributions will be valuable to others. Finally, establishing group identity and promoting personal responsibility are also useful ways of increasing cooperation in a knowledge-sharing dilemma.

\section{Restructuring the Pay-off Function}

Changing the perceived pay-off structure is one of the factors most often cited for promoting cooperation in social dilemmas (Bonacich et al. 1976; Kelley and Grzelak 1972; Kollock 1998; Komorita et al. 1980; Van Lange et al. 1992). If the cost of contributing to a discretionary database is lower, the benefits associated with defecting will also be lower. Likewise, an increase in the incentives associated with sharing one's knowledge will also increase cooperation. Thus, the closer one can bring net costs to zero, by either lowering the cost or increasing the benefit of contributing, the less profitable, and thus less tempting, defecting will be.

One immediate way to reduce perceived costs is simply to make it easier for people to share information. Jarvenpaa and Staples (2000) have found 
that people who feel more comfortable with technology are more likely to engage in electronic information exchanges. Well-designed, user-friendly groupware simplifies the task and reduces the time necessary to distribute one's ideas. Information about the existence of such systems and the availability of training opportunities can also help people to use the systems more efficiently and thus reduce the perceptions of cost. Another way to reduce the perceived costs of sharing information is for organizations to assure that employees have the time and resources necessary for making their knowledge available to others. If a project manager in a consulting firm is allowed to incorporate into the project's budget the human resources needed to compile and share the lessons learned during the project, the 'opportunity cost' that would normally be associated with such a task is clearly reduced.

Researchers in social cooperation have proposed two ways to increase individual pay-offs: through a cooperation-contingent transformation, or through a public-good transformation (Kerr 1992). In a cooperation-contingent transformation, a selective incentive or reward is offered, which is contingent on an individual's behaviour. A selective incentive of this sort can change the nature of the situation so that a social dilemma no longer exists. Cooperating becomes the dominant strategy, because receiving the reward maximizes the individual's gain. As a result, the individual and collective interests coincide (Kalman 1999). In a public-good transformation, the perceived value of the collective gain is increased. If the value of the collective gain is greater for the individual than the cost, then the incentive to cooperate will increase. Again, the social dilemma disappears, because the dominant strategy is to cooperate in the hope of maximizing the collective gain. Some researchers of social dilemmas have used valueexpectancy theory to try to explain collective behaviour (Klandermans 1992; Kalman 1999; Staw 1984). According to this theory, an individual's behaviour is a function of the perceived likelihood, or expectancy, that his or her behaviour will result in a valued outcome. The higher the expectancy and the more the person values the outcome, the more likely the behaviour (Vroom 1964). Value-expectancy theory then predicts that the more an employee values the collective gain, the more likely that he or she will contribute.

In order to increase individual incentives to exchange knowledge, organizations can explore either of these two options. The first solution would be to selectively reward individual contributions by means of some kind of participation-contingent compensation. The reward does not have to be monetary. Non-monetary rewards, such as social recognition, can be extremely powerful incentives so long as they are public, infrequent, credible, and culturally meaningful (Lawler 2000). Of course, the use of selective incentives carries a cost for the organization - the monitoring of participation for administering the rewards, plus the rewards themselves and has the added disadvantage that it might yield quantity at the expense of quality. A highly subsidized system might encourage employees to artificially inflate their number of contributions, even at the expense of disre- 
garding their quality. Therefore, while the subsidies may well succeed in increasing cooperation, they can also jeopardize the value of the ideas being shared, making it a profitable game for everyone but the firm itself!

Perhaps a better strategy would be to increase the perceived value of the collective gain. Although probably more difficult to achieve, this approach has the advantage that employees will be more likely use their best judgement concerning their contributions in order to maximize collective gains. As Kalman (1999: 22) points out, 'a public-good transformation would support a participative, self-managed use of shared database to communicate'. One potential intervention to increase the value of the collective gain would be to combine a knowledge-exchange programme with a gain-sharing or profit-sharing plan (Lawler 2000) in which every individual receives a bonus based on the success of the knowledge-sharing programme. The reward thus depends on the combined efforts of the individual and the other people with whom he or she exchanges knowledge. Given that the employee's contributions should benefit the work of other group members, these contributions should also increase the potential value of the gain-sharing bonus the employee will receive.

There is a clear difference between this solution and that of selective incentives. In this case, an employee is not rewarded directly for contributing to the shared database. The motivation to contribute comes from the fact that the employee will receive a reward if the knowledge-sharing programme is successful. The employee contributes information to the discretionary database because he or she values the collective gain: the higher the collective gain, the higher the employee's bonus. In their study of contributions to a discretionary database, Connolly et al. (1992) found a significant positive relationship between a group-wide incentive for cooperation and contribution rate.

Like selective incentives, these kinds of practices carry an overhead cost. However, since gain-sharing plans are, by definition, linked to group effectiveness, the overhead should be justified by truly realized value, thus reducing the risk of subsidizing hot air, as in the case of selective incentives. Another advantage of gain-sharing programmes over the use of selective rewards is that they encourage quality rather than quantity. Notice that this solution is not the same as setting up a traditional gain-sharing plan. The proposed solution requires that the organization set up a group-wide incentive, not around a functional area or a geographical unit, but around a knowledge-sharing community that will often cut across traditional divisions. Finally, this type of solution may have the added benefit of increasing the commitment of employees towards their knowledge community, a factor that some experts consider to be a requisite for the creation of intellectual capital (Ulrich 1998; Wasko and Faraj 2000).

Perhaps the most important cost associated with knowledge sharing is the vulnerability that may be assumed by revealing one's personal insight in certain organizational contexts. In a scenario where employees' incentives are aligned with extraordinary performance, sharing one's skills with others may harm one's capacity to outperform the rest. In order to eliminate 
this barrier, organizations could expand the concept of performance to include, in addition to business results, contributions towards building the organization's strategic capabilities. One of the most direct ways for an organization to achieve this transformation is to align its human resource policies - selection criteria, performance appraisal, job definitions, career management, training and development, and compensation - with this new role demanded from employees (see Welbourne et al. 1998). This organizational shift is, in fact, so deep that it even affects the nature of the psychological contract between the employee and the company: from a commitment on the part of the employee to seek outstanding performance to a commitment to also help create outstanding organizational capabilities. The firm sends unequivocal messages regarding the value of building employee's long-term commitment (Ulrich 1998).

\section{Increasing Efficacy}

In the social-dilemma literature, there is significant empirical evidence showing a positive relationship between perceived efficacy and levels of cooperation (Kerr 1992; Kerr 1989; Rapoport et al. 1989; Van de Kragt et al. 1983). Some studies have found that individuals who report higher judgements of efficacy are more likely to cooperate (Kerr 1989; Rapoport et al. 1989). Other studies have manipulated group size to show its negative impact on cooperation (Messick and Brewer 1983; Orbell and Dawes 1981). Often, the fact that cooperation declines as group size increases is attributed to the perception that the impact of one's contribution on the group outcome declines with group size (Kerr 1992). Van de Kragt et al. (1983) found evidence that when an individual believes that his or her participation is critical for the provision of the public good, willingness to cooperate will increase.

The expectancy-value theory can again be used to explain these results. It predicts that people's willingness to act is directly affected by their expectations about the potential effects of their actions. When people believe that their actions will not have a clear and discernible effect on the value of the shared good, they will be less likely to cooperate than when they perceive a direct link between their participation and the value their help creates. Expectancy can be thought of as a function of two distinct types of efficacy: information self-efficacy and connective efficacy (Kalman 1999). Information self-efficacy refers to an employee's belief that the information he or she has would be helpful to co-workers, were they to receive it. Expectancy will be higher if individuals believe that the information they have can truly increase the value of the shared good. Connective efficacy is the belief that others will actually receive the information if it is contributed. An employee may believe that he or she has valuable information and yet may not expect that contributing this information will increase the value of the shared good, because the person does not believe that relevant others will receive the information.

One way to increase both the perceived efficacy of individual contributions 
Table 1

Examples of Interventions

Aimed at

Restructuring the Pay-off Function
Intervention Objective

Advanced information technology

Rewards or selective incentives

Gain-sharing programmes

Align human resource policies with participation
- Reduce cost of contributing

- Increase benefit of contributing

- Increase perceived value of collective gain

- Increase benefit of contributing

- Send clear message about importance of knowledge exchange and creation for the organization

and perceived connective efficacy in the context of knowledge exchange is to establish mechanisms by which employees receive feedback whenever others use their contributions. The simple act of receiving feedback should increase perceptions of connective efficacy. Employees see that, in fact, others have received the information that they posted. The content of the feedback will also provide an indication of the impact of one's work on the progress of the community, thus increasing the perceived efficacy of one's efforts. It should be noted that negative feedback might reduce an employee's information self-efficacy and, consequently, reduce the likelihood that the employee will choose to contribute to the database in the future. However, this may not be a negative consequence of the use of feedback. It could actually help control for the quality of contributions and compensate for the possible negative effects of selective incentives, thereby encouraging quantity rather than quality.

Given the state-of-the-art of information technology, implementing this feature would be quite simple. It often just requires a modification of current information workflow definitions. For example, IBM's database includes a rating scale on the first page of each contribution, so that users can rate the usefulness of the information. Then, each time a new rating is provided, the system can have this rating automatically forwarded to the employee who contributed the information. Despite the additional costs imposed on members of these peer-review systems, they have certain advantages, such as spreading the overhead cost of evaluation among all participants, encouraging employees to monitor the quality of their contributions, and establishing further knowledge-creating opportunities by requiring a deeper processing of each other's contributions.

In addition to information self-efficacy and connective efficacy, employees need to be assured that there will be a minimum critical mass of contributions to the knowledge repository (Markus 1990; Marwell and Oliver 1993; Oliver et al. 1985). If the number of contributors is too small, the value of the collective good may not be high enough to offset the individual cost of participation. An employee may have both information self-efficacy and connective efficacy, yet will choose not to participate in knowledge-sharing because he or she does not feel there is a big enough group to create a useful database of information. In addition to economies of scale and scope, strategic alliances and mergers have the added advantage of allowing 'knowledge economies' through the re-use of existing 
knowledge stocks (Hansen et al. 1999), an idea that helps to explain ongoing mergers in the management-consulting business. An interesting finding is that, as an individual's personal efficacy increases, so does his or her sense of collective efficacy (Kerr 1992). Therefore, interventions aimed at increasing information efficacy should also increase perceptions that the collective knowledge-sharing venture will be successful.

Although the need for a critical mass suggests that small groups may not be ideal for organizational knowledge exchange, we have already mentioned that cooperation has been found to decline as groups become larger (Kollock 1998). When people interact with large communities, they may perceive that their contributions do not make a big difference. In fact, both information self-efficacy and connective efficacy may decline with group size. Larger groups may lead to higher redundancy rates in the repositories, thus harming both the probability of employees making valuable contributions and the probability of users finding what they need. Both of these problems, increased redundancy and search difficulty, could be solved through the adoption of advanced technology. New search and indexing techniques, often borrowed from artificial intelligence, can assist users in finding the most useful piece of information in the knowledge base in each particular situation (Davenport and Prusak 1998). The larger the knowledge repositories become, and the larger the potential value of using the information, the more investments in solutions like these will be justified.

A final potential solution to increasing employees' perceived efficacy is via training. As previously mentioned, employees may not feel that their contributions are helpful - a lack information efficacy, or they are not convinced that other employees will receive the information that they contribute - a lack of connective efficacy. A training programme that teaches individuals how to make knowledge contributions and how to use the company's knowledge-sharing tools effectively could increase both types of efficacy. The content of such a training programme might include tips as to what type of information is most valuable, how information could best be presented, etc. Often, employees may not recognize what types of experiences are worth sharing, or may not know exactly how to put their experiences into words. Training that makes them aware of the type of information that is most useful, and how to present that information so that it is most helpful to others, would be likely to increase levels of information efficacy.

Training is also useful to teach employees how to effectively search for needed information. This type of training serves two purposes. First, it impacts connective efficacy. If employees see that others are being trained in effective ways of using the knowledge-sharing system, they are more likely to believe that others will receive the information that they post on the system. A second positive outcome is that it increases the likelihood that employees will use an information database to look for ideas or information that may help them in their work. Although most research concerned with knowledge sharing focuses on the difficulties associated with 
Table 2

Examples of Interventions

Aimed at Increasing the

Efficacy of

Contributions

\begin{tabular}{ll}
\hline Intervention & Objective \\
\hline Provide feedback to contributors & $\begin{array}{l}\text { - Increase information efficacy } \\
\text { - Increase connective efficacy } \\
\text { - Create further opportunities for knowledge } \\
\text { combination and creation through deeper }\end{array}$ \\
Ensure a critical mass of participants & $\begin{array}{l}\text { - Make potential value of shared knowledge } \\
\text { greater than individual cost }\end{array}$ \\
Advanced technology & $\begin{array}{l}\text { Increase information efficacy by reducing } \\
\text { redundancies }\end{array}$ \\
& $\begin{array}{l}\text { - Increase connective efficacy by reducing } \\
\text { search difficulties }\end{array}$ \\
Training & - Increase information efficacy \\
& - Increase connective efficacy
\end{tabular}

encouraging knowledge contributions, another very important area is that of the actual use of information repositories. Training in how to use an information-sharing system should increase their use by making employees aware of the valuable information that exists and showing them how to access that information quickly and efficiently.

\section{Promoting Group Identity and Personal Responsibility}

Numerous studies of social dilemmas have found a sense of group identity to influence contributions to a public good (Bornstein et al. 1990; Brewer and Kramer 1986; Dawes et al. 1988; Kollock 1998; Kramer and Brewer 1986; Rapoport et al. 1989). Kramer and Brewer (1984) showed that individuals were more likely to exercise personal restraint in a common-rights dilemma, simply because they are identified as being members of a group that can exercise those rights. In studies of knowledge sharing, Bonacich and Schneider (1992) found that, once groups were shown to have a common identity, individuals began to share more information. Also, Connolly and colleagues (1992) discovered that, by giving very small bonuses to a group, contributions to a shared database could be increased. Given that these bonuses were very small, they concluded that they were symbolic, but nevertheless they served to create an in-group identity that had a positive influence on contribution rates.

Van Lange et al. (1992: 20) suggested that 'group identity leads to feelings of we-ness and personal responsibility, which enhances self-restraint'. In fact, a study of a public-good dilemma by Fleishman (1980) revealed a positive relationship between feelings of responsibility and cooperation. Both group identity and personal responsibility act as forms of social control, which has been shown to be a powerful way of maintaining cooperation. Axelrod (1984) explained that the probability of cooperating increases when (a) interactions among participants are frequent and durable, (b) participants are easily identifiable, and (c) there is sufficient information available about each individual's actions. If it is likely that the individuals will not interact again in the future, if the identity of the other participants is 
unknown. If there are no records of past interactions, there will be an incentive for individuals to free-ride, because there will be no way of making people accountable for their actions. If individuals feel that they belong to a common group, both past and future interactions with other group members are more likely and the identity of other group members is more often known.

The third factor that increases the probability of cooperation, noted by Axelrod, is if information is available about the actions of each individual. Studies have shown identifiability to be an important determinant of cooperative behaviour (Fox and Guyer 1978; Kahan 1973), and it may also help to reduce the diffusion of responsibility that so often occurs in groups. It has been well documented that individuals are less helpful when other people are around (Latané and Darley 1968; Latané and Rodin 1969). This is most often attributed to the lack of personal responsibility felt by individuals in a group. Identifiability not only increases feelings of personal responsibility, but it also impacts individuals' reputations, which are also powerful mechanisms of social control (Kollock 1998).

The following organizational interventions may help to establish group identities and a sense of personal responsibility for contributing to the shared database. Numerous researchers have suggested that communication is a valuable tool for establishing group identity (Dawes 1991; Messick and Brewer 1983; Van Lange et al. 1992). Encouraging communication among employees regarding the information-sharing programme should promote their sense of belonging to a knowledge-sharing community. This communication should increase employees' feelings of commitment to the collective welfare (Orbell et al. 1988). It also fulfils Axelrod's (1984) conditions for social control by promoting frequent interactions and identifiability.

In reviewing the literature regarding the cooperation-enhancing effect of communication, Dawes et al. (1990) concluded that this effect might be due to one of two explanations. Group discussion may either increase feelings of group identity or it may increase commitment. Kerr and KaufmanGilliland (1994) tested these two hypotheses. Their results failed to confirm the group-identity explanation for the positive effects of communication on cooperation; however, they provided strong support for the commitment explanation. Content analyses of group discussion revealed a high rate of committing to cooperate. Further analyses showed that individuals who agreed to cooperate had higher rates of actual cooperation. So, although there is no consensus as to whether communication increases cooperation by enhancing feelings of group identity or by increasing individuals' commitment to cooperate, there is strong evidence to support the fact that group discussion will increase levels of contributions.

Another interesting result of Kerr and Kaufman-Gilliland's (1994) study was that discussion increased the expectation that others would cooperate. Research has shown that an individual's expectation that others will participate is positively related to the likelihood that the individual will also cooperate (Dawes et al. 1977; Schroeder et al. 1983; Van Lange et al. 1992). 
Table 3

Examples of Interventions

Aimed at Increasing Group

Identity and

Personal

Responsibility

\begin{tabular}{ll}
\hline Intervention & Objective \\
\hline Encourage communication & - Increase sense of group identity \\
& - Increase commitment \\
& - Increase frequency of interactions \\
& - Increase expectations of others' participation \\
$\begin{array}{l}\text { Create knowledge-sharing } \\
\text { communities or communities of }\end{array}$ & - Increase sense of group identity \\
practice & - Increase frequency of interactions \\
Publicize information about & - Increase identifiability \\
employees' contributions &
\end{tabular}

This, then, is an added advantage of communication. Consequently, facilitating communication among potential contributors to a shared database should help to increase contributions. Group meetings may be established where employees are encouraged to discuss the information-sharing programme. These group discussions should increase contribution rates, either because they enhance group identity or because they lead to commitments to contribute. They should also increase levels of cooperation by raising expectations that others will also participate.

The establishment of knowledge-sharing communities or communities of practice may also enhance feelings of group identity. Recall that studies have shown that contributions to a discretionary database increased simply by making group identity salient (Bonacich and Schneider 1992; Connolly et al. 1992). Thus, a possible solution to the knowledge-sharing dilemma may be to create knowledge-sharing groups and make it clear to employees that they belong to a specific group. Any small reminder of group belonging, such as communications to group members, group meetings, etc., should help to keep group identity salient. Group meetings have the additional advantage of providing opportunities for employees to communicate, thus increasing interactions, identifiability and, consequently, feelings of personal responsibility.

Finally, identifiability may also be increased by publicizing information about employees' contributions to the information database. For example, a monthly newsletter could include a list of all employees who contributed to the knowledge-sharing system over the last month. Sharing this information makes clear to everyone which employees have taken the time to contribute to the common good and which have not. Employees' reputations will certainly be affected by this information and this type of social control should increase participation. Publishing the names of contributors serves the additional purpose of a selective incentive in the form of social recognition for contributions. 


\section{Conclusions}

The ideas presented in this paper rely on two basic premises. First, a requisite for the creation of collective knowledge is the exchange of information among individuals and groups within the organization. Second, collective knowledge is an important source of competitive advantage. Consequently, fostering a rich flow of knowledge exchange within the organization can be an important source of competitive advantage. The question is: how can firms manage to encourage this information exchange?

Information technology experts have developed highly sophisticated tools (groupware, discretionary databases, intranets, knowledge-management systems, workflow technology) to support the exchange of organizational insights across time and distance barriers. However, it has become clear that technology is only one of the ingredients for successful knowledge exchange. The other, even more important, requisite is that of a social environment which encourages or even enforces knowledge sharing.

Several scholars and practitioners have proposed heuristics that can help to create this type of social environment (Nevis et al. 1995). These include creating a climate of openness, showing a commitment to education and development, demonstrating involved leadership, creating a 'knowledgefriendly' culture, reducing turnover, increasing organizational commitment, communicating the benefits of knowledge exchange, rewarding individual participation, and redesigning work processes and jobs.

This paper has tried to offer a theoretical framework that allows us to address these possible interventions in a more congruent way. The framework borrows the concept of 'social dilemma' from the social sciences. By treating a knowledge-exchange situation as a variation of the classic 'public-good dilemma', we can build upon five decades of empirical research in order to identify the organizational interventions that may have a significant impact on facilitating knowledge sharing.

While the value of sharing knowledge might be obvious to the organization, from an individual standpoint, sharing knowledge can carry significant costs which can even offset the potential benefits. The literature on social dilemmas provides several guidelines as to how to help a group shift towards a cooperative mode. Some of the solutions are aimed at restructuring the pay-off structure of the exchanges, by either reducing the cost of contributing one's ideas or emphasizing the benefits associated with exchanging personal insights with one's co-workers. Other solutions are geared towards increasing people's perceptions of efficacy, that is, making people aware of the impact that their engagement in information exchanges can have on the performance of others. Finally, a third type of intervention tries to foster cooperation by enhancing employees' sense of group identity and personal responsibility.

For each of these types of solutions, we have identified concrete practices, some of which have already been applied in organizations. These practices are of a very diverse nature. Some have to do with how the information 
systems should be designed, while others have to do with the organization's structure, or its human resource policies. The analysis illustrates that knowledge management is multidisciplinary in nature. Successful knowledge management initiatives may thus require the coordination of multiple functional areas of the organization.

Collective knowledge requires not only that valuable information is shared among individuals and groups within an organization, but also that employees feel motivated and empowered to explore and try out new ways of carrying out their work, to detect and analyze improvement opportunities along the entire value chain, to think and act creatively and embrace innovation. Our proposal only highlights potential solutions for the supply side of knowledge exchanges. Prior research on creativity, organizational learning and quality may provide valuable guidance in identifying and analyzing the whole set of behaviours necessary to leverage an organization's collective knowledge, but additional work is required along these lines as well.

Finally, our paper is theory building and does not provide empirical evidence as to the effectiveness of the specific practices discussed. It does, however, provide a theoretical background for the development of future empirical studies that address information sharing within organizations. While we have cited a few examples of studies of this kind, it is fair to say that information-sharing behaviour has still not received the research attention it deserves, given it's relevance for current organizational practice. The social-cooperation framework we have presented provides a good source of concrete, falsifiable hypotheses.

Note

* This research was funded in part by the IBM Airtel Human Research Center at the Instituto de Empresa and by a grant to the second author from the Spanish Commission of Science and Technology (No. SEC2000-0395).

\section{References}

Anand, Vikas, Charles C. Manz, and William H. Glick

1998 'An organization memory approach to information management'. Academy of Management Review 23/4: 796-809.

Axelrod, Robert

1984 The evolution of cooperation. New York: Basic Books.

Barney, Jay B.

1991 'Firm resources and sustained competitive advantage'. Journal of Management 17: 99-120.

Blackler, Frank

1995 'Knowledge, knowledge work and organizations: An overview and interpretation'. Organization Studies 16/6: 1021-1047.
Boisot, Max H.

1998 Knowledge assets. Oxford: Oxford University Press.

Boland, Richard J., Ramkrishnan V. Tenkasi, and Dov Te'eni

1994 'Designing information technology to support distributed cognition'. Organization Science 5/3: 456-475.

Bonacich, Phillip, Gerald H. Shure, James P. Kahan, and Robert J. Meeker

1976 'Cooperation and group size in the n-person prisoner's dilemma'. Journal of Conflict Resolution 20: $687-706$. 
Bonacich, Phillip, and Sherry Schneider 1992 'Communication networks and collective action' in Social dilemmas: Theoretical issues and research findings. W. B. G. Liebrand, D. M. Messick, and H. A. M. Wilke (eds.), 225-245. New York: Pergammon.

Bornstein, Gary, Ido Erev, and Ori Rosen 1990 'Intergroup competition as a structural solution to social dilemmas'. Social Behavior 5: 247-260.

Brewer, Marilynn B., and Roderick M. Kramer

1986 'Choice behavior in social dilemmas: Effects of social identity, group size, and decision framing'. Journal of Personality and Social Psychology 50: 543-549.

Cabrera, Ángel, and David Allen

1999 'The architecture of organizational cognition'. Paper presented at the Annual Conference of the Academy of Management. Chicago, IL.

Connolly, Terry, and Brian K. Thorn

1990 'Discretionary databases: theory, data, and implications' in Organizations and communication technology. J. Fulk and C. Steinfield (eds.), 219-233. London: Sage.

Connolly, Terry, Brian K. Thorn, and Alan Heminger

1992 'Discretionary databases as social dilemmas' in Social dilemmas: Theoretical issues and research findings. W. B. G. Liebrand, D. M. Messick, and H. A. M. Wilke (eds.), 199-208. New York: Pergammon.

Cook, Scott D. N., and John Seely Brown

1999 'Bridging epistemologies: the generic dance between organizational knowledge and organizational knowing'. Organization Science 10/4: 381-400.

Dawes, Robyn M.

1980 'Social dilemmas'. Annual Review of Psychology 31: 169-193.
Dawes, Robyn M.

1991 'Social dilemmas, economic selfinterest, and evolutionary theory' in Frontiers of mathematical psychology: Essays in honor of Clyde Coombs. D. R. Brown and J. E. K. Smith (eds.), 53-79. New York: Springer-Verlag.

Dawes, Robyn M., Jeanne McTavish, and Harriet Shaklee

1977 'Behavior, communication, and assumptions about other people's behavior in a commons dilemma situation'. Journal of Personality and Social Psychology 35: 1-11.

Dawes, Robyn M., John Orbell, and Alphons J. C. Van de Kragt

1988 'Not me or thee but we: The importance of group identity in eliciting cooperation in dilemma situations'. Acta Psycologica 68: 83-97.

Dawes, Robyn M., Alphons J. C. Van de Kragt, and John Orbell

1990 'Cooperation for the benefit of us not me, or my conscience' in Beyond self interest. J. Mansbridge (ed.), 97-110. Chicago: University of Chicago Press.

Davenport, Thomas H., David W. De Long, and Michael C. Beers

1998 'Successful knowledge management projects'. Sloan Management Review 39/2: 43-57.

Davenport, Thomas H., and Lawrence Prusak

1998 Working knowledge. Cambridge, MA: Harvard Business School Press.

De Long, David W., and Liam Fahey

2000 'Diagnosing cultural barriers to knowledge management'. Academy of Management Executive 14/4: 113-127.

Fleishman, John A.

1980 'Collective action as helping behavior: Effects of responsibility diffusion on contributions to a public good'. Journal of Personality and Social Psychology 38/4: 629-637. 
Fowler, Alan

2000 'The role of AI-based technology in support of the knowledge management value activity cycle'. Journal of Strategic Information Systems 9/1: 107-128.

Fox, John, and Melvin Guyer

1978 "Public choice" and cooperation in n-person prisoner's dilemma'. Journal of Conflict Resolution 22/3: 469481.

Gupta, Anil K., and Vijay Govindarajan

2000 'Knowledge management's social dimension: Lessons from Nucor Steel'. Sloan Management Review 42/1: 71-80.

Hansen, Morten T., Nitin Nohria, and Thomas Tierney

1999 'What's your strategy for managing knowledge?' Harvard Business Review 77/2: 106-116.

Hardin, Garrett

1968 'The tragedy of the commons'. Science 162: 1243-1248.

Jarvenpaa, Sirkka L., and D. Sandy Staples

2000 'The use of collaborative electronic media for information sharing: An exploratory study of determinants'. Journal of Strategic Information Systems 9/1: 129-154.

Kahan, James P.

1973 'Non-interaction in an anonymous three-person prisoner's dilemma game'. Behavioral Science 18: 124-127.

Kalman, Michael E.

1999 'The effects of organizational commitment and expected outcomes on the motivation to share discretionary information in a collaborative database: Communication dilemmas and other serious games'. Doctoral dissertation. University of Southern California.

Kelley, Harold H., and Janusz L. Grzelak

1972 'Conflict between individual and common interest in an $\mathbf{n}$-person relationship'. Journal of Personality and Social Psychology 21: 190-197.
Kerr, Norbert L.

1989 'Illusions of efficacy: The effects of group size on perceived efficacy in social dilemmas'. Journal of Experimental Social Psychology 25: 287-313.

Kerr, Norbert L.

1992 'Efficacy as a causal and moderating variable in social dilemmas' in Social dilemmas: Theoretical issues and research findings. W. B. G. Liebrand, D. M. Messick, and H. A. M. Wilke (eds.), 59-80. New York: Pergammon Press.

Kerr, Norbert L., and Cynthia M.

Kaufman-Gilliland

1994 'Communication, commitment, and cooperation in social dilemmas'. Journal of Personality and Social Psychology 66/3: 513-529.

Klandermans, Bert

1992 'Persuasive communication: Measures to overcome real-life social dilemmas' in Social dilemmas: Theoretical issues and research findings. W. B. G. Liebrand, D. M. Messick, and H. A. M. Wilke (eds.), 307-318. New York: Pergammon.

Kollock, Peter

1998 'Social dilemmas: the anatomy of cooperation'. Annual Review of Sociology 22: 183-205.

Komorita, Samuel, J. Sweeney, and David A. Kravitz

1980 'Cooperative choice in the n-person dilemma situation'. Journal of Personality and Social Psychology 38/3: 504-516.

\section{KPMG}

2000 Knowledge management research report 2000. KPMG Consulting Reports.

Kramer, Roderick M. and Marilynn B. Brewer

1984 'Effects of group identity on resource use in a simulated commons dilemma'. Journal of Personality and Social Psychology 46/5: 1044-1057. 
Kramer, Roderick M., and Marilynn B. Brewer

1986 'Social group identity and the emergence of cooperation in resource conservation dilemmas' in Experimental social dilemmas. $\mathrm{H}$. Wilke, D. M. Messick, and C. G. Rutte (eds.), 205-234. Frankfurt: Verlag/ Peter Lang.

Lado, Augustine A., and Mary C. Wilson

1994 'Human resource systems and sustained competitive advantage: A competency-based perspective'. Academy of Management Review 19/4: 699-727.

Lam, Alice

2000 'Tacit knowledge, organizational learning and societal institutions: An integrated framework'. Organization Studies 21/3: 487-513.

Latané, Bibb, and John M. Darley

1968 'Group inhibition of bystander intervention in emergencies'. Journal of Personality and Social Psychology 10: 215-221.

Latané, Bibb, and Judith Rodin

1969 'A lady in distress: Inhibiting effects of friends and strangers on bystander intervention'. Journal of Experimental Social Psychology 5: 189 202.

Lawler, Edward E. III

2000 Rewarding excellence. San Francisco, CA: Jossey-Bass.

Levitt, Barbara, and James G. March

1988 'Organizational learning'. Annual Review of Sociology 14: 319-340.

Markus, M. Lynne

1990 'Toward a "critical mass" theory of interactive media' in Organizations and communication technology. J. Fulk and C. W. Steinfield (eds.), 194-218. Newbury Park, CA: Sage.

Marwell, Gerald, and Pamela Oliver

1993 The critical mass in collective action: A micro-social theory. Cambridge, MA: Cambridge University Press.

Merali, Yasmin

2000 'Individual and collective congruence in the knowledge management process'. Journal of Strategic Information Systems 9/1: 213-234.
Messick, David M., and Marilynn B. Brewer

1983 'Solving social dilemmas: A review' in Review of personality and social psychology. L. Wheeler and $\mathrm{P}$. Shaver (eds.), 11-44. Beverly Hills: Sage.

Monge, Peter R., Janet Fulk, Michael E. Kalman, Andrew J. Flanagin, Claire Parnassa, and Suzanne Rumsey

1998 'Production of collective action in alliance-based interorganizational communication and information systems'. Organization Science 9/3: 411-433.

Moore, Karl, and Julian Birkinshaw

1998 'Managing knowledge in global service firms: Centers of excellence'. Academy of Management Executive 12/4: 81-92.

Nahapiet, Janine, and Sumantra Ghoshal

1998 'Social capital, intellectual capital and the organizational advantage'. Academy of Management Review 23/2: 242-267.

Nanda, Ashish

1996 'Resources, capabilities and competencies' in Organizational learning and competitive advantage. $\mathrm{B}$. Moingeon and A. Edmonson (eds.), 93-120. London: Sage.

Nelson, Richard R., and Sidney G. Winter

1982 An evolutionary theory of economic change. Cambridge, MA: Harvard University Press.

Nevis, Edwin C., Anthony J. DiBella, and Janet M. Gould

1995 'Understanding organizations as learning systems'. Sloan Management Review 36/2: 73-85.

Nonaka, Ikujiro

1994 'A dynamic theory of organizational knowledge creation'. Organization Science 5: 14-37.

Nonaka, Ikujiro, and Hirotaka Takeuchi

1995 The knowledge-creating company: How Japanese companies create the dynamics of innovation. New York: Oxford University Press. 
Oliver, Pamela, Gerald Marwell, and Ruy Teixeira

1985 'A theory of critical mass: Interdependence, group heterogeneity, and the production of collective action'. American Journal of Sociology 91: 522-556.

Olson, Mancur

1965 The logic of collective action. Cambridge, MA: Harvard University Press.

Olson, Judith, S., Thomas K. Card, Gary M. Landauer, Thomas M. Olson, and John Leggett

1993 'Computer-supported co-operative work: research issues for the 90's'. Behavior and Information Technology 12/2: 115-129.

Orbell, John M., and Robyn M. Dawes

1981 'Social dilemmas' in Progress in applied social psychology. G. Stephenson and J. H. David (eds.), 37-65. New York: Wiley.

Orbell, John M., Alphons J. C. Van de Kragt, and Robyn M. Dawes

1988 'Explaining discussion-induced cooperation'. Journal of Personality and Social Psychology 54: 811-819.

Quinn, James Brian, Philip Anderson, and Sydney Finkelstein

1996 'Leveraging intellect'. Academy of Management Executive 10/3: 7-26.

Rapoport, Amnon, Gary Bornstein, and Ido Erev

1989 'Intergroup competition for public goods: Effects of unequal resources and relative group size'. Journal of Personality and Social Psychology 56: 748-756.

Sanchez, Ron, and Aimé Heene

1997 'A competence perspective on strategic learning and knowledge management' in Strategic learning and knowledge management. $\mathrm{R}$. Sanchez and A. Heene (eds.), 3-15. New York: Wiley.

Schroeder, D. A., T. D. Jensen, A. J Reed, D. D. Sullivan, and M. Schwab

1983 'The actions of others as determinants of behavior in social trap situations'. Journal of Personality and Social Psychology 19: 522-539.
Spender, J.-C.

1996 'Competitive advantage from tacit knowledge?' in Organizational learning and competitive advantage. B. Moingeon and A. Edmonson (eds.), 56-73. London: Sage.

Staw, Barry M.

1984 'Organizational behavior: A review and reformulation of the field's outcome variables'. Annual Review of Psychology 35: 627-666.

Sweeney, John W.

1973 'An experimental investigation of the free-rider problem'. Social Science Research 2: 277-292.

Tsoukas, Haridimos

1996 'The firm as a distributed knowledge system: A constructionist approach'. Strategic Management Journal 17/1: $11-25$.

Ulrich, Dave

1998 'Intellectual capital $=$ competence $\times$ commitment'. Sloan Management Review 39/2: 15-26.

Van de Kragt, Alphons J. C., John Orbell, and Robyn M. Dawes

1983 'The minimal contributing set as a solution to public goods problems'. American Political Science Review 77: $112-122$.

Van Lange, Paul A., Wim B. G. Liebrand, David M. Messick, and Henk A. M. Wilke

1992 'Introduction and literature review' in Social dilemmas: Theoretical issues and research findings. W. B. G. Liebrand, D. M. Messick, and H. A. M. Wilke (eds.), 59-80. New York: Pergammon.

Vroom, Victor $\mathrm{H}$.

1964 Work and motivation. New York: Wiley.

Wasko, Molly McLure, and Samer Faraj

2000 " "It is what one does": why people participate and help others in electronic communities of practice'. Journal of Strategic Information Systems 9/1: 155-173.

Welbourne, Theresa, M., Diane E. Johnson, and Amir Erez

1998 'The role-based performance scale: Validity analysis of a theory-based measure'. Academy of Management Journal 41/5: 540-555. 
Wenger, Etienne C., and William M. Snyder 1999 'Communities of practice: The organizational frontier'. Harvard Business Review (Jan.-Feb.): 139-145.

Wernerfelt, B.

1984 'A resource-based view of the firm'. Strategic Management Journal 5: 171-180.
Winter, Sidney G.

1996 'Organizing for continuous improvement: Evolutionary theory meets the quality revolution' in Organizational learning. M. D. Cohen and L. S. Sproull (eds.), 460-483. Thousand Oaks, CA: Sage. 